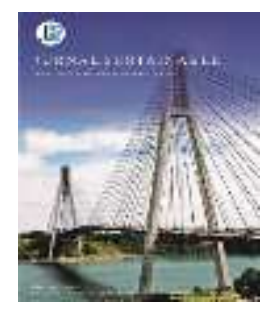

\title{
Pemanfaatan Low Resolution Prototype (LRP) pada Engineering Design Process (EDP) di Jurusan Teknik Elektro Universitas Maritim Raja Ali Haji (UMRAH)
}

\author{
Deny Nusyirwan*, \\ Jurusan Teknik Elektro, Fakultas Teknik, Universitas Maritim Raja Ali Haji \\ Jl. Politeknik Senggarang, Tanjungpinang 29115 \\ *Corresponding Author : denynusyirwan@umrah.ac.id
}

\begin{abstract}
The aplication of Low Resolution Prototype (LRP) in the Engineering Design Process will affect the succesfull of an innovation in the higher education institutions, therefore, it is really an excellent foundation if the engineering schools of universities are able to provide students with engineering background, to be able to understand the engineering design process (EDP) in general and benefits of low resolution prototype during the innovation processes. This paper will explain the basic concept, understanding and will be given explanations that emphasizes on the use of low resolution prototype in research or development of an innovation as the solution for in the communities for the present and future problems.
\end{abstract}

Keywords - Research, Low Resolution, Innovation

Intisari- Pemanfaatan Low Resolution Prototype (LRP) didalam proses perancangan teknik (engineering design process) sangatlah mempengaruhi tingkat keberhasilan dari sebuah inovasi di sebuah perguruan tinggi, oleh sebab itu, adalah merupakan sebuah landasan yang sangat baik apabila di setiap perguruan tinggi pada tahun awal perkuliahan sudah membekali mahasiswa dengan latar belakang teknik (engineering) untuk mampu memahami engineering design process secara umum dan pemanfaatan purwarupa sederhana (low resolution prototipe) secara maksimal. Dalam tulisan ini, akan diterangkan terlebih dahulu konsep dan pengertian dasar pemahaman dan selanjutnya akan diberikan penjelasan yang menitikberatkan pada pemanfaatan low resolution prototipe pada penelitian atau pun pengembangan sebuah inovasi yang kedepannya dapat merupakan soulisi untuk permasalahan di masyarakat.

Kata Kunci - Penelitian, Low Resolution, Inovasi

\section{Pendahuluan}

Engineering Design Process (EDP) adalah merupakan sebuah rangkaian tahapan didalam melakukan perancangan yang harus dilalui oleh seorang peneliti dan perancang (researcher and designer) dengan latar belakang teknik. Tahapan ini dimulai dengan studi ke masyarakat secara sosial (social research) untuk melakukan pengumpulan informasi-informasi dan juga observasi mengenai permasalahan-permasalahan (problems) dan kebutuhan-kebutuhan (need) pada sebuah lingkungan yang ada di masyarakat. Sebagai contoh yang paling sederhana adalah dalam bidang kuliner untuk menentukan cita rasa makanan, dimana hingga saat ini masyarakat yang tinggal di daerah Sumatra Barat, Manado dan Gorontalo sangat 
menikmati makanan yang bercita rasa pedas, sedangkan masyarakat di daerah jawa tengah yang lebih dominan ke cita rasa manis, sehingga untuk mereka yang ingin sukses membuka usaha kuliner sebagai contoh rumah makan, juga harus memperhatikan hal tersebut. Seperti halnya seorang yang akan membuka usaha rumah makan, seorang research and design engineer juga harus memperhatikan kebiasaan masyarakat di daerah setempat agar teknologi yang di hasilkan atau dikembangkan nantinya akan dapat di aplikasikan secara tepat dan bermanfaat kepada kehidupan di masyarakat, oleh sebab itu perlu dilakukan observasi awal yang dikenal dengan istilah ethnography.

\section{MeTODE ENGINEeRING DESIGN Process (EDP)}

\section{A. Etnography}

Etnography adalah merupakan bagian awal dari EDP, dimana dalam observasi tahapan ini diperlukan pendekatan secara sosial (social approach) dan memerlukan jangka waktu tertentu didalam pelaksanaannya di lapangan.

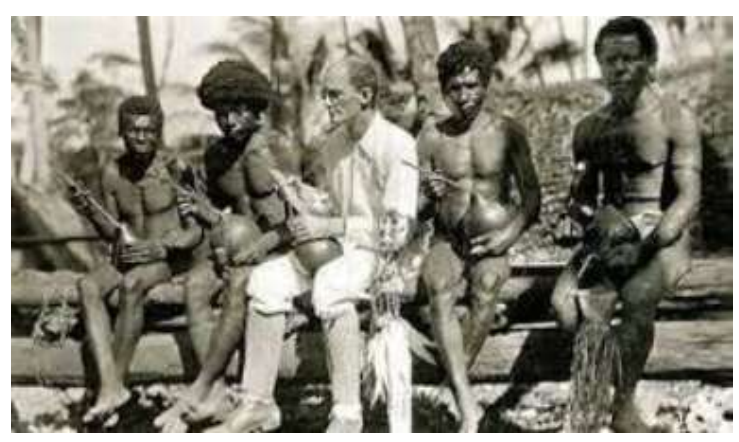

Gambar 1. Pendekatan secara sosial

Pendekatan secara sosial berupa hidup bersama di lingkungan masyarakat dan melakukan aktifitas seperti biasa di masyarakat setempat. Selanjutnya melakukan pendataan mengenai pola hidup masyarakat tersebut yang akan dijadikan sebagai masukan untuk produk atau usaha yang akan di kembangkan di masyarakat atau komunitas tersebut.

Adapun prinsip dasar dalam melakukan etnography ini adalah emphaty, dimana peneliti diminta untuk melihat dari berbagai sudut pandang (think out of the box) untuk mendapatkan dan mengumpulkan informasi sebanyak-banyaknya.

Adapun didalam empathy ini memiliki beberapa aturan yang akan mendukung tingkat keberhasilan didalam pengumpulan data :

- Menumbuhkan sikap untuk mampu menghargai sesama (appreciate them as human being)

- Mampu untuk berkomunikasi dengan tanpa memberikan penilaian (no judgment)

- Mampu untuk memahami perasaan (understanding their feeling)

- Mampu melihat kehidupan di masyarakat secara objektif (see their world).

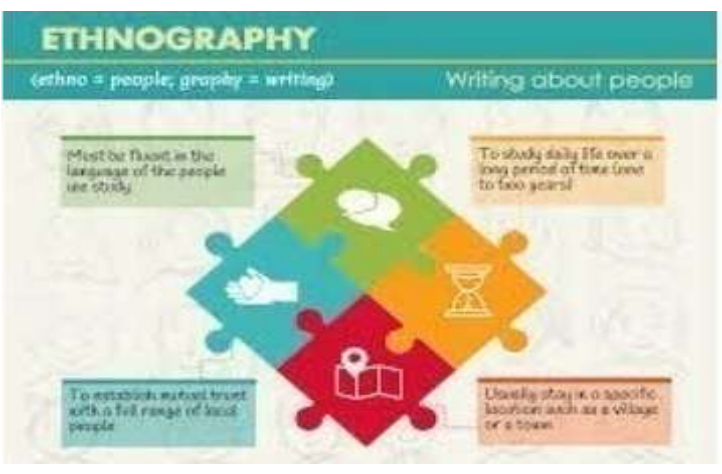

Gambar 2. Etnography

\section{B. Design Thinking}

Design thinking adalah merupakan inti (core) dari EDP, dengan memprioritaskan agar semua luaran dari proses ini akan dapat menghasilkan produk yang highly userfriendly and innovative, selain itu juga merupakan solusi untuk merubah pola hidup masyarakat menjadi lebih baik (transform the way people live).

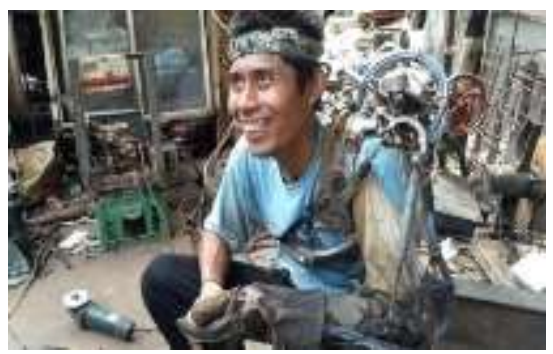

Gambar 3. Interaksi Manusia dan Mesin sebagai luaran Design Thinking 


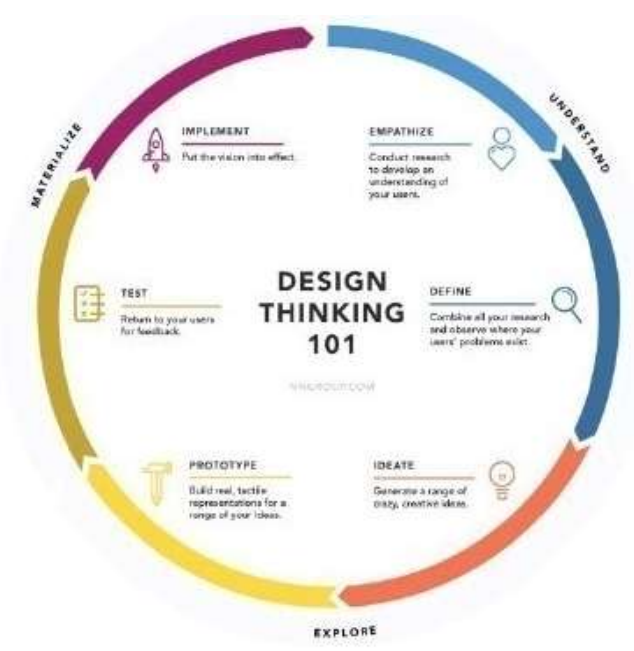

Gambar 4. Tahapan didalam Design Thinking

Dalam tahapan awal Design Thinking ini, seorang rekayasawan diminta untuk mampu melakukan observasi dengan berusaha untuk dapat mengerti mengenai kebutuhan pengguna (user need) dan menemukan permasalahan yang ada di masyarakat, melalui sebuah proses yang dinamakan emphaty, Tahapan ideation, adalah merupakan tahapan untuk mengeluarkan ide-ide yang luar biasa (crazy idea) untuk memberikan solusi terhadap permasalahan yang ada di masyarakat, dalam tahapan ini sangatlah diharapkan untuk tidak adanya tindakan untuk memberikan penilaian negatif secara langsung karena akan dapat mengakibatkan timbulnya rasa tidak percaya diri pada seseorang yang memberikan usulan. Tahapan ini juga di kenal dengan istilah brainstorming.

\section{Curahan Pendapat (Brainstorming)}

Tidak ada ide dan usulan yang salah, semua usulan diterima dan sangat dihargai, dengan demikian semua anggota akan termotivasi untuk memberikan usulan solusi terkait permasalahan yang dibicarakan.

Didalam proses brainstorming ini, sangatlah diharapkan semua ide-ide yang disampaikan dapat dilakukan secara cepat, oleh sebab itu diperlukan dokumentasi yang juga cepat, pemanfaatan Post-Its sebagai alat bantu sangat bermanfaat didalam tahapan awal ideation, selanjutnya bisa dilakukan dengan mempergunakan tanah liat (clay).

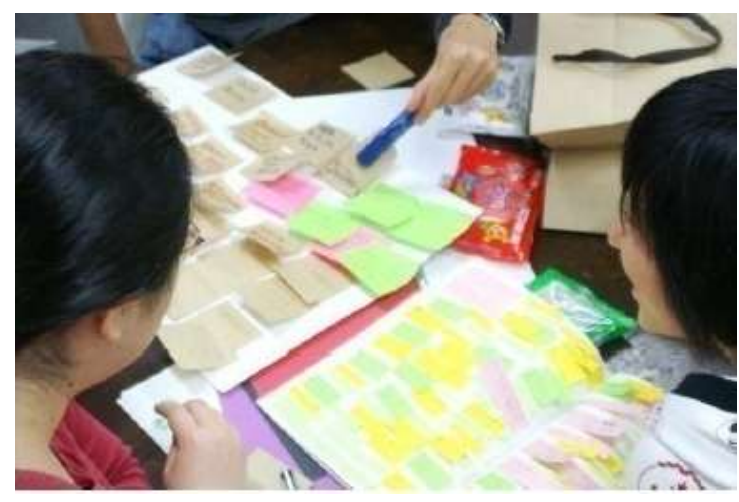

Gambar 5. Proses Brainstorming dengan mempergunakan Post-Its.

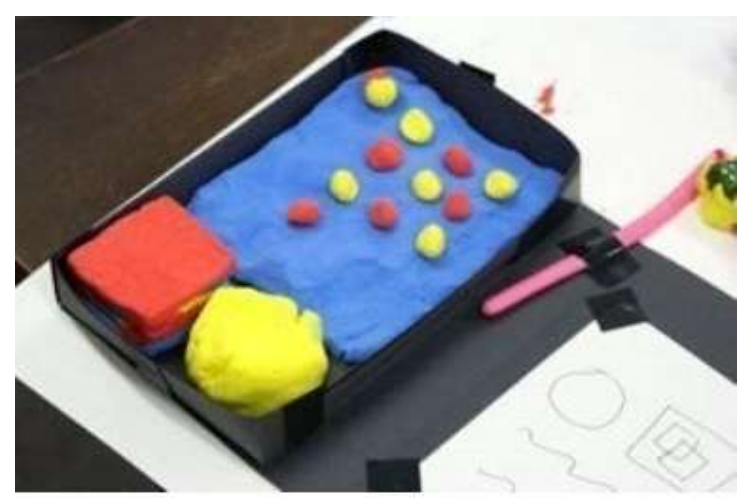

Gambar 6. Proses Brainstorming dengan mempergunakan tanah liat (Clay)

\section{Purwarupa ( Prototyping)}

Tahapan pembuatan purwarupa (prototype) adalah merupakan tahapan lanjutan dari EDP, dimana dalam tahapan ini sudah mulai memerlukan tahapan perencanaan lanjutan. Beberapa tahapan dari prototype yang saat ini sudah di kenal di perguruan tinggi dan industri adalah Low Resolution Prototype (LRP ), Middle Resolution Prototype (MRP ) dan High Resolution Prototype (HRP ). Selain itu juga dikenal istilah digital prototyping dan rapid prototyping.

\section{- Low Resolution Prototype}

Istilah low resolution prototype atau yang lebih dikenal dengan istilah purwarupa sederhana dengan nilai ekonomis yang sangat rendah adalah merupakan tahapan yang sering dilakukan oleh para perancang (designer) dan rekayasawan (engineer) untuk mendapatkan 
pengalaman pertama dari pengguna (user experience) mengenai alat ataupun teknologi yang akan di hasilkan nantinya.

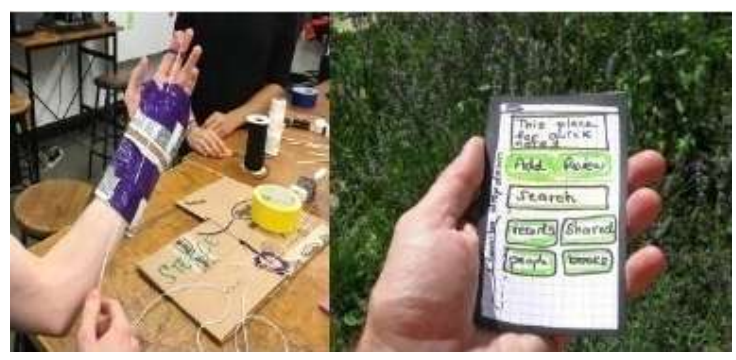

Gambar 7. Low Resolution Prototype

Perguruan tinggi di Singapore seperti National University Singapore (NUS) dengan program studi Design Centric Program, School of Engineering dari Nanyang Polytechnic dan Singapore University of Technology (SUTD) telah menerapkan pola ini menjadi sebuah landasan untuk setiap pembuatan dan uji coba prototipe. Selain itu pemerintah Singapore juga telah membentuk sebuah design council yang terdiri dari akademisi dan rekayasawan, yang bertugas untuk memberikan dukungan kepada industri terkait akselerasi di dalam perancangan produk yang akan dipasarkan.

Dalam tahapan ini, uji coba dan simulasi masih dilakukan secara internal dan biaya murah, dimana semua anggota yang ikut merancang diminta untuk memberikan pendapatnya. Selanjutnya dilakukan tahapan middle dan high resolution prototype. Pada high resolution prototype akan memerlukan pembiayaan yang besar karena prorotipe yang akan dihasilakan sudah akan mendekati/ sudah mendekati rancangan sebenarnya.

\section{Pembahasan}

Jurusan Teknik Elektro UMRAH telah memeperkenalkan Engineering Design Process (EDP) kepada mahasiswa sejak di semester awal perkuliahan, dimana low resolution prototype merupakan satu faktor penting didalam perancangan. Beberapa contoh projek yang telah dipergunakan didalam membantu pemahaman mahasiswa mengenai LRP adalah sebagai berikut :

\section{Low Resolution Prototype pada Projek Boat Shield.}

Observasi yang dilakukan oleh seorang mahasiswa yang berasal dari sebuah perkampungan nelayan di kota tanjungpinang, terhadap pengguna perahu pompong ( merupakan penamaan untuk bermotor di tanjungpinang ) saat ini, adalah dalam rangka perkuliahan metodelogi penelitian, dimana dalam proposal penelitian ini menitik beratkan kepada faktor kenyamanan untuk penumpang pompong dengan cara mengusulkan rancangan yang sesuai dengan memperhatikan kondisi cuaca selama dalam perjalanan.

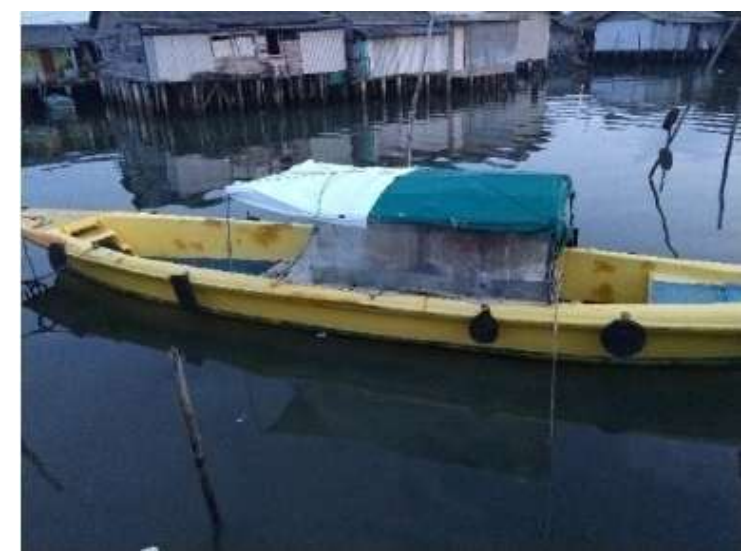

Gambar 8. Pompong Tanjungpinang

Diawali dengan studi Etnografi, mengumpulkan data mengenai jenis pompong yang saat ini dipergunakan untuk pompong dari kampung bugis tujuan pelabuhan laut jaya, tanjung pinang.

Selanjutnya jenis Low Resolution Prototype $(L R P)$ yang di usulkan mahasiswa setelah melakukan proses brainstorming dan design thinking. 


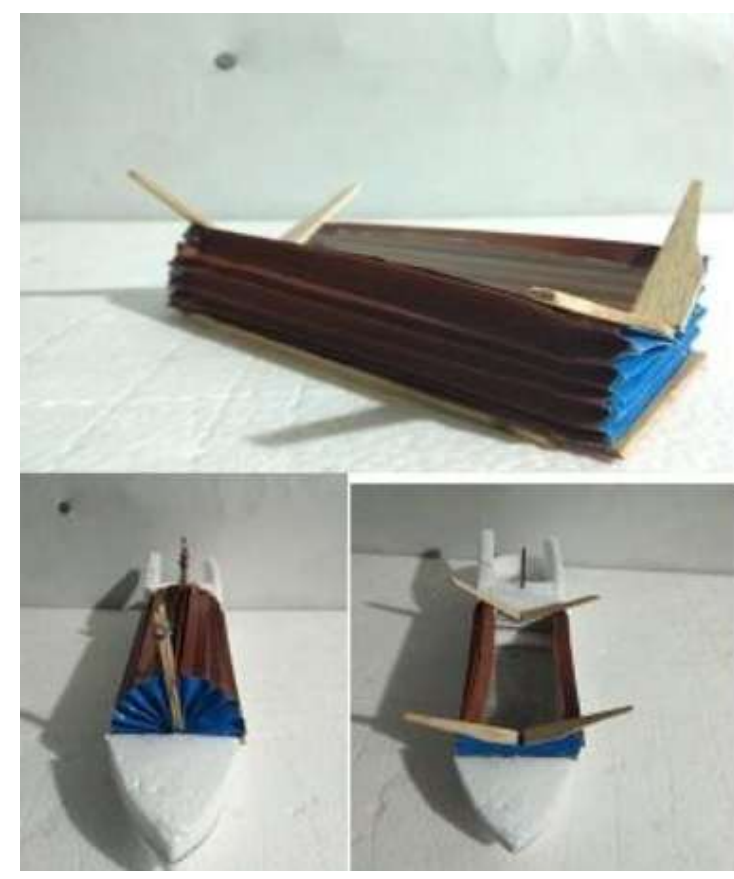

Gambar 9. LRP untuk tenda pelindung pada perahu Pompong

\section{Low Resolution Prototype pada Projek penangkap sampah pada permukaan air laut}

Observasi ini dilakukan oleh seorang mahasiswi jurusan teknik elektro FT UMRAH yang tinggal di daerah Tanjung Uban, dimana dengan berkembangnya suatu daerah dan bertambahnya jumlah penduduk juga akan diikuti dengan bertambahnya kapasitas sampah yang berada di darat dan di laut. Oleh sebab itu, dinas kebersihan terkait juga telah menugaskan petugas untuk membersihkan sampah-sampah yang terdapat di permukaan laut secara tradisionil dengan menggunakan perahu.

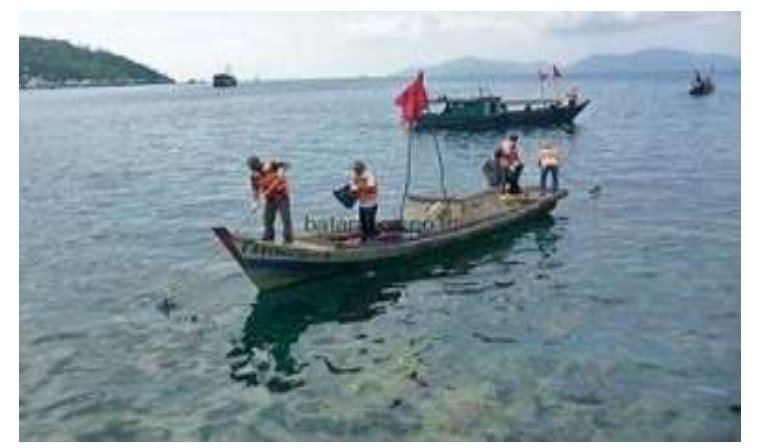

Gambar 10. Petugas Pembersih Sampah Laut pergunakan perahu
Setelah melakukan proses brainstorming dan design thinking maka alat untuk penangkap sampah pada permukaan laut harus mampu bergerak naik turun dengan berbagai ketinggian gelombang untuk dapat mengumpulkan semua sampah yang mengambang atau yang terdapat pada permukaan.

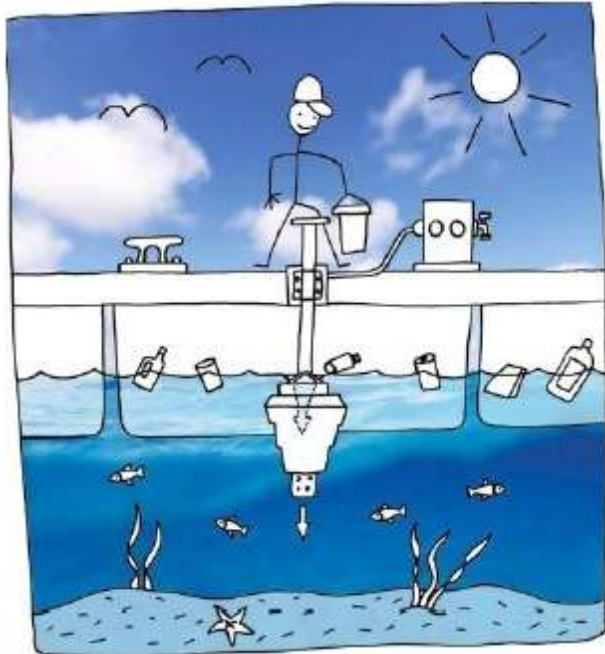

Gambar 11. Design Thinking Concept untuk penangkap sampah pada permukaan air laut

Selanjutnya air yang disedot dari permukaan dan melewati kantong tangkapan yang dipasang di dalam alat, selanjutnya dengan dengan menggunakan pompa air yang dihubungkan langsung ke stopkontak. Air kemudian dipompakan kembali ke laut meninggalkan sampah yang terperangkap di dalam kantong tangkapan untuk dibuang.

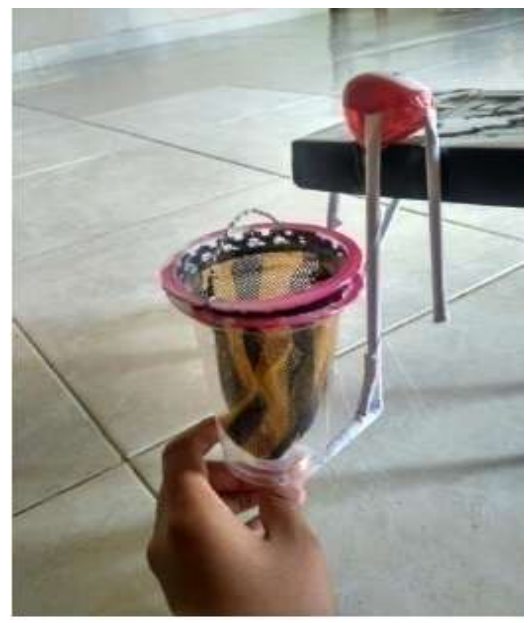

Gambar 12. LRP untuk penangkap sampah pada permukaan air laut 


\section{Low Resolution Prototype pada Pengendali Otomatis untuk mengatur posisi awal pada sebuah perahu wisata yang sedang berlabuh.}

Pemanfaatan jangkar oleh kapal ataupun perahu untuk berlabuh, dimanfaatkan untuk dapat mempertahankan posisi kapal tetap pada posisi awalnya. Daerah Bintan yang terkenal dengan akan pariwisatanya, telah lama mengembangkan wisata bawah air (underwater tourism) dan memancing (fishing) yang hingga saat ini menjadi agenda wisata tahunan. Didalam observasi yang telah dilakukan oleh seorang mahasiswa asal kijang, dimana ketika melakukan wisata menyelam (diving) dan manggrove tour, perahu yang dipergunakan untuk berlabuh akan cenderung jangkar perahu tersebut akan terkait terumbu karang dan selanjutnya merusak terumbu karang tersebut. Hal ini tentu akan berlawanan dengan prinsip untuk kelestarian lingkungan.

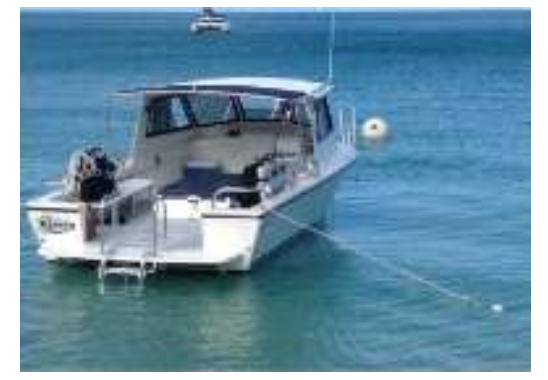

Gambar 13. Ilustrasi sebuah perahu bermotor yang sedang berlabuh menggunakan jangkar.

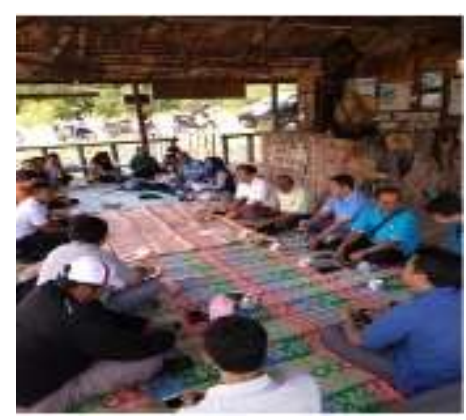

Gambar 14. Brainstorming bersama pengusaha jasa pariwisata mengenai pola berlabuh pada perahu yang membawa wisatawa

Dengan melalui brainstorming mengenai akibat yang dapat ditimbulkan akibat berlabuh menggunakan jangkar, dan setelah melalui proses brainstorming, maka diusulkan untuk merancang perahu pariwisata yang dilengkapi dengan pengendali posisi otomatis ( automatic positioning system).

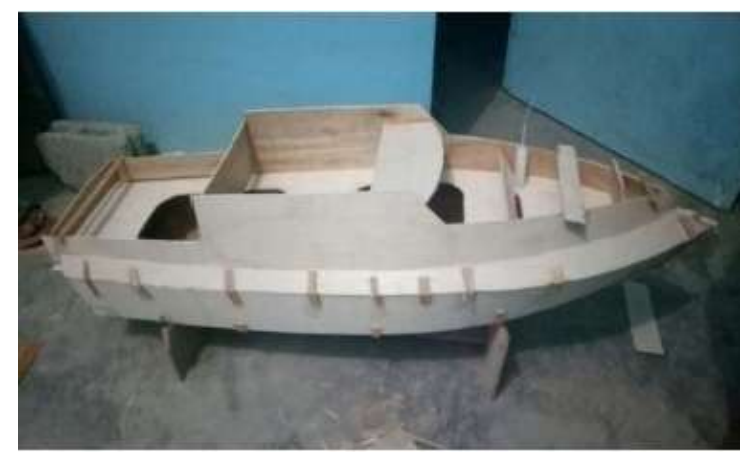

Gambar 15. LRP Pengendali Otomatis untuk mengatur posisi awal pada sebuah perahu wisata yang sedang berlabuh.

\section{Low Resolution Prototype pada Projek pompa otomatis pengatur ketinggian air pada perahu penumpang.}

Observasi yang dilakukan oleh seorang mahasiswa UMRAH dari keluarga nelayan ini, dilakukan pada pelabuhan penyebrangan pompong di wilayah kampong bugis, tanjungpinang. Awalnya dengan memperhatikan secara etnografi mengenai permasalahan utama yang dapat menimbulkan masuknya air kedalam perahu ketika tidak dipergunakan, yaitu : akibat hujan yang secara berterusan. Pada saat ini beberapa pemilik perahu menggunakan penutup berupa kain terpal.

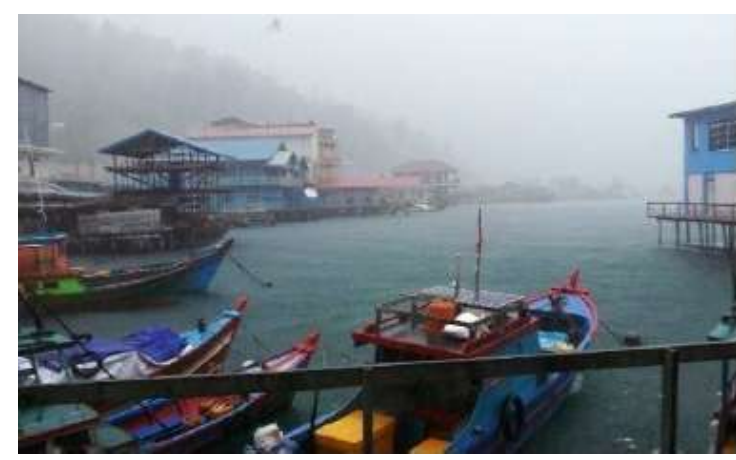

Gambar 16. Studi etnografi untuk obervasi mengenai permasalahan yang dapat menimbulkan masuknya air kedalam perahu penumpang, sebagai contoh : hujan 


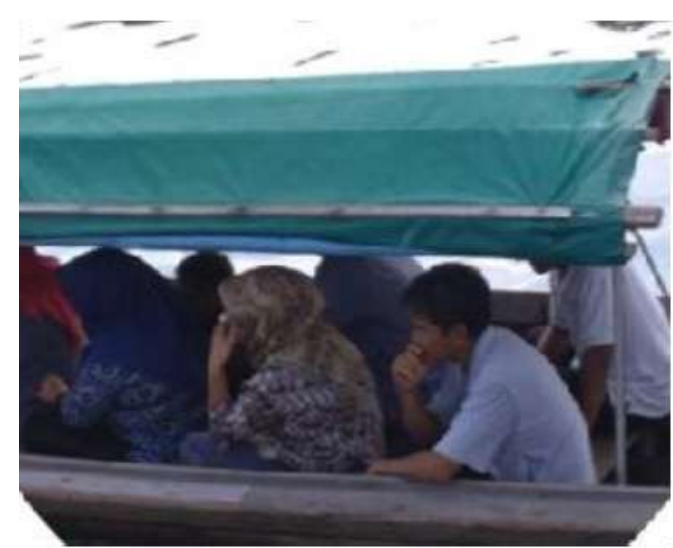

Gambar 17. Penggunaan kain terpal pada perahu di daerah kampung bugis, Tanjungpinang

Setelah melalui proses brainstorming dan design thinking maka diusulkan penggunaan android untuk melakukan monitoring dan kontrol untuk menghidupkan pompa pengurasan air dari dalam pompong apabila ketinggian air sudah melebihi batas yang ditentukan. Dan adapun bentuk Low Resolution Prototipe yang ditampilkan adalah sebagai berikut :

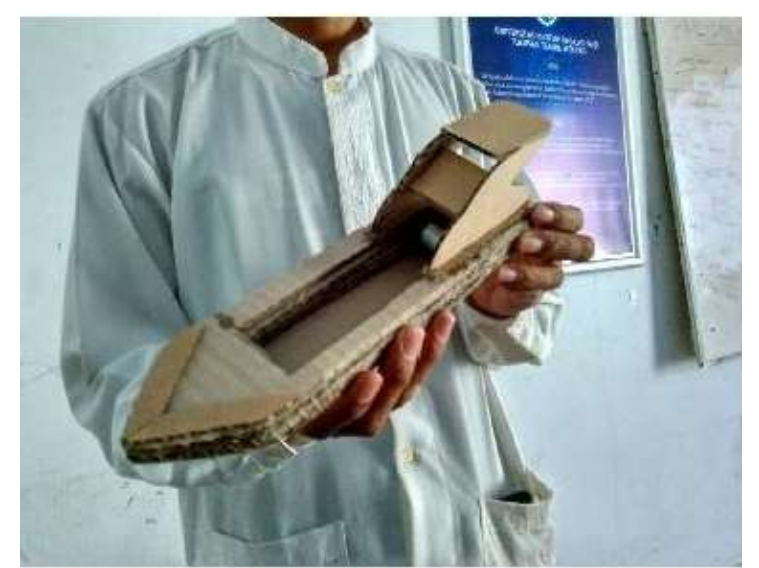

Gambar 18. Low Resolution Prototype dari perahu pompong

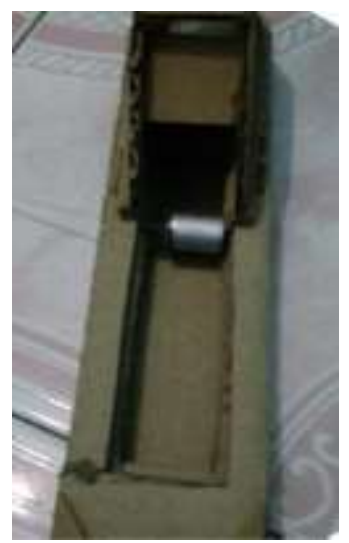

Gambar 19. Lokasi penempatan Pompa pada perahu Pompong

\section{KESIMPULAN}

Penelitian (research) dan Inovasi adalah merupakan sebuah investasi waktu dan biaya, dimana memerlukan manajemen dan strategi yang baik didalamnya, oleh sebab itu didalam pola pengajaran dan perkuliahan, dimana pemanfaatan Low Resolution Prototype (LRP) telah membantu mahasiswa jurusan teknik elektro UMRAH didalam pemahaman sebuah konsep dari inovasi yang akan dirancang dan dapat melakukan re-design secara cepat di tahapan awal perancangan (initial design), dimana selanjutnya akan dapat mengurangi pengeluaran/biaya selama proses perancangan (low cost engineering design process).

Dengan mempergunakan bahan-bahan yang mudah didapat seperti kardus bekas, tempat air mineral, pipa sedotan air, dimana semua bahan-bahan tersebut hampir sama sekali tidak mengeluarkan biaya, mahasiswa jurusan teknik elektro FT UMRAH dilatih dan berusaha untuk mampu menyampaikan ide-ide kreatif nya sebagai solusi terhadap permasalahan yang ada di masyarakat, dimana merupakan tujuan utama dari EDP itu sendiri. yang telah dicontohkan : boat shield, penangkap sampah pada permukaan laut, Pengendali Otomatis untuk mengatur posisi awal pada sebuah perahu wisata yang sedang berlabuh dan pompa otomatis pengatur ketinggian air pada perahu penumpang.

Sebagaimana yang telah dilakukan oleh mahasiswa/i jurusan teknik elektro UMRAH, proses pemahaman mengenai pemanfaatan low resolution prototype ini juga telah dilakukan oleh beberapa perguruan tinggi di Singapore seperti University of Singapore (NUS) dengan Program Studi Innovation \& Design Centric Programme (iDCP) Singapore University of Technology and Design (SUTD), Nanyang Polytechnic (NYP), School of engineering. Pada ahirnya, sangat diharapkan kedepannya bahwa LRP akan mampu mengakselerasikan penelitian untuk dapat menghasilkan inovasiinovasi yang merupakan solusi untuk permasalahan di masyarakat. 
Nusyirwan, Pemanfaatan Low Resolution Prototype (LRP) pada Engineering Design Process (EDP) di Jurusan Teknik Elektro Universitas Maritim Raja Ali Haji (UMRAH)

\section{UCAPAN TERIMA KASIH}

Terima kasih kepada ketua jurusan dan rekan di jurusan teknik elektro serta redaksi jurnal Sustainable yang telah memberikan kesempatan melakukan penelitian dan publikasi mengenai pemanfaatan Low Resolution Prototype di jurusan teknik elektro UMRAH.

\section{REFERENSI}

[1] Interaction Design Foundation The Encyclopedia of Human-Computer Interaction, 2nd Ed [Daring]. Tersedia pada : https://www.interactiondesign.org/literature/book/theencyclopedia-of-human-computerinteraction-2nd-ed/ethnography, Diakses : 17 Mei 2018 ].

[2] University College London (UCL), Anthropology and ethnography [Daring].

Tersedia pada : http://www.ucl.ac.uk/why-wepost/about-us/what-is-anthropology , [ Diakses : 17 Mei 2018 ].

[3] A Medium Corporation Ethnography: The First Step in Design Thinking [Daring]. Tersedia pada : https://medium.com/mediaethnography/ethnography-the-first-stepin-design-thinking-d3c533278978, Diakses : 17 Mei 2018 ].

[4] Arm Orthoses - Low Resolution Prototypes [Daring]. Tersedia pada : https:// depts..washington .edu/uwsteele/2015/10/28/arm-orthoseslow-resolution-prototyping, [ Diakses : 17 Mei 2018 ].

[5] Sarah Gibbons, Design Thinking 101 [Daring]. Tersedia pada : http:// www.nngroup.com/articles/designthinking, [ Diakses : 17 Mei 2018 ]. 